\title{
South-south comparisons: a syntegrated approach to the teaching of the Arts for primary school teacher preparation in South Africa and Australia
}

\begin{abstract}
In light of the tendency to present the arts in an integrated fashion in many education systems world-wide, this article examines the consequences of integration for discrete art forms. In particular the advantages of adopting a syntegrated approach to the facilitation of arts in teacher preparation are investigated and recommended. A specific comparison between the implementation of arts curricula in South Africa and Australia is made. The disjuncture between policy and practice in arts education, reported internationally, needs constant monitoring. We conclude that the heart of curriculum transfer and transformation is in the classroom.
\end{abstract}

\section{Background}

The authors of this article have significant experience in teacher preparation, van Niekerk and Klopper in both South Africa and Australia, where Klopper currently lectures in this field. Formerly Klopper spent six years in classroom teaching followed by three years as an Education Specialist: Arts and Culture for the Gauteng ${ }^{\mathrm{i}}$ education department in South Africa. Van Niekerk has previously lectured teacher trainees at three universities in Perth, when she was invited as Distinguished Visiting Scholar to the University of Western Australia. Vermeulen has been involved in teacher preparation for over a decade and recently completed her doctorate in Arts education, with reference to South Africa, but drawing deeply on Australian experience. She employed a qualitative research strategy with purposive sampling of 
best practices found in South African schools. Klopper’s doctoral study, on the other hand, was quantitative, focused on a random sampling of South African schools. The combination of insights from three authors with contrasting research paradigms adds to triangulation and validation of the research findings. The authors admit to a music bias, as their original studies were specifically in music, but their combined interests in this article are in the preparation of teachers for Arts education. The creative arts will be referred to as Arts education in this article. This term is proffered as encompassing music, dance, drama, visual arts and media. Through this article we propose a syntegrated approach to the teaching of Arts education ${ }^{\mathrm{ii}}$ in primary school teacher preparation and in making the decisions which need to be taken and supported by policy makers nationally and internationally ${ }^{\mathrm{iii}}$.

\section{Integration as a world tendency in Arts education}

The integration of the arts in education is an internationally debated phenomenon: it is a modern trend to organise the curriculum in an integrated and interdisciplinary manner (Aaron 1994; Barrett 2001; Burton 2001; Chrysostomou 2004; Hauptfleisch 1997; Klopper 2004; Russell-Bowie 2006 and 2008; Snyder 2001; Vermeulen 2009). Integration has, however, always been a part of traditional African music. Through the ages, the African culture and way of life have embraced the arts in an integrated way - music, song and dance have always been performed as a unity in such a way that Western methods of division and categorisation are superfluous (Levine 2005, Nzewi 2003; Oehrle 2002). Without basic literacy skills, African people are capable of making music, including the abilities to compose, dance and arrange movements for songs. It is only since the colonisation of the African continent that Western thought and methods have permeated the education of the young, leading to the 
splitting up and classification of different facets in the arts (Vermeulen 2009).

In the current curricula of both South Africa and Australia, integrated subject areas generate the formation of new insights and connections between various disciplines. “Interdisciplinary education enables students to identify and apply authentic connections between two or more disciplines and/or to understand essential concepts that transcend individual disciplines” (Consortium of National Arts Education Associations 2002, 3). A further motivation for an integrated curriculum is that problems in the real world are seldom limited to one discipline - they require a multidisciplinary approach (Loepp 1999, 2). The view is supported that an integrated Arts education can equip learners with skills to cope with real-life situations.

The authors concur with Russell-Bowie’s $(2008,603)$ important contribution towards finding feasible ways of integrating various disciplines and arts. She argues that in order to survive a crowded curriculum, many teachers have opted to integrate across the curriculum to provide learners with holistic learning experiences. In her view there are various models of integration. These include:

\section{- Service connections}

This method of integration is based on the premise that, in the presentation of a key learning area, a teacher borrows an element or activity from another discipline without including any concepts or knowledge of the discipline which they borrowed from. An example would be where learners sing the “Alphabet Song” in a language lesson to help them remember the alphabet letters, but without learning anything about music. In this instance, music is in 
the service of the language discipline.

- Symmetric correlations

These correlations divide emphasis equally between the various disciplines involved. Referring to the "Alphabet song” example, this would include aspects of the form of the song being explored in the music lesson: adding a listening example of variations of the same theme by Mozart; the alphabet being used as a spelling tool in a language lesson; and the origin of the Western alphabet from its Arabic roots being investigated in a history lesson. This method uses common resources or material, which in this instance is the alphabet. Through this method, barriers between learning areas are broken down while specific results are achieved for each discipline.

- Syntegration

Russell-Bowie has coined this term by joining the words "synergy" and "integration". Combining the meaning of these two terms is in essence what this form of integration implies. The term synergy refers to the potential ability of people to be more successful in working together than on their own. Syntegration, then, means that "the outcomes achieved [...] are greater than if each key learning area was taught by itself” (Russell-Bowie 2006, 260). She then describes a unit based on Impressionism, where a variety of disciplines spanning the arts as well as languages and history are all involved to give learners a vivid experience of this style period. Syntegration as an educational method encourages holistic and real-life experiences. Although an overarching theme is chosen for these types of lessons, knowledge and skills for the 
discrete disciplines are not "blurred for the sake of the theme".

The debate around integrating different disciplines with each other started receiving progressively more emphasis in the late 1980s, and in 1999 was predicted by Loepp to be a topic “destined to receive a lot of attention soon". This has proved to be the case, with many countries opting for integrated curricula, such as both South Africa and Australia. The challenge, however, is to find the most effective ways by which this can be implemented, maintaining the integrity of each discipline in an integrated arts curriculum.

\section{South African past and status quo}

Within the last two decades the South African educational landscape has undergone several innate changes. The former education system was fragmented and uneven. Some schools had first world education programs which included Music and Visual Art, and other schools barely survived, struggling to teach the basic skills of reading, writing and arithmetic. This resulted in classroom time being allocated to the teaching of literacy and numeracy to compensate for the backlog. It was evident that this approach was not sustainable or educationally equitable.

When the first democratic government was established in 1994, a new curriculum was created to encompass the needs of all the people. Policy makers realised that it is a basic human right for all learners ${ }^{\text {iv }}$ to be exposed to and educated in the arts. An integrated curriculum was devised and recommended for implementation to compensate for the vast discrepancies of the past. However, the proposed curriculum implementation could not provide instant relief for the years of inequitable education 
practices. The process of implementation, with all its pitfalls, is still ongoing.

The most recent curriculum iteration, implemented in 2002 (South Africa, 2002), requires of individual primary school teachers to educate learners in four discrete art forms: music, dance, drama and visual art. One difficulty negatively influencing the delivery of quality Arts education is that of principals allocating the learning area to generalist teachers with "free periods" in their time table, with little or no effort to employ specialists for the arts programs, even though such specialists may be on the staff of the schools (Vermeulen 2009, 4-24). A consequence is schools being unable to provide continuity for or quality of Arts education. This manifests in the devaluation of Arts education as a learning area.

During July 2009, a task team of experts was appointed by the South African Minister of Education to investigate the implementation of the National Curriculum (South Africa. DoE 2009, 5). This panel observed that support for teachers during the implementation of the curriculum was not sufficient, often being "too generic and superficial”. They concluded that a "one size fits all” approach would not provide the necessary depth and quality, suggesting that teacher preparation should be "subject specific” (South Africa. DoE 2009, 10).

The same conclusions on the topic of the preparation of teachers were drawn in the research conducted by Vermeulen, where teachers delivering Arts education did not have specific training in the art forms they were required to teach. In these instances, little emphasis is placed on the unique and additional artistic skills that the arts require. Skills are seen in relation to the collection of information, reducing the arts to theoretical subjects (Vermeulen 2009, 4-17). 
A comparison of time allocation for each discrete art form within the Arts and Culture learning area revealed that there is a natural bias towards the art form in which the teacher is most skilled. The findings of Vermeulen's research indicated that $45 \%$ of the total time allocated to the arts in primary schools was dedicated to visual art, while music received only 27\% (2009, 4-27). The explanation provided by teachers was that visual art activities are time consuming and focus on individual skill development. However, emphasising visual art at the cost of the other art forms has negative consequences for the holistic education of learners.

The current South African curriculum should directly influence primary school teacher preparation; however, there is no formal synchronization of arts courses between schools and tertiary institutions and between courses presented at the various South African universities (Vermeulen 2009, 4-54). At most higher education institutes, an overview of the various art forms is given, without focussing on the development of knowledge and specific skills in each discrete art form - and, as noted by Brinkman (2010, 49), “a certain set of skills must be in place to flourish as a (music) teacher”. Research findings by the task team of the Curriculum Review Report (South Africa. DoE 2009) as well as several other studies (Klopper 2004, Rijsdijk 2003 and Vermeulen 2009) point out that the preparation of primary school teachers needs urgent revision and adaptation to address the challenges experienced in the implementation of Arts education in South African schools.

\section{Status quo in Australia}

Education in Australia is primarily the responsibility of states and territories. There 
are six states and two mainland territories constituting the Commonwealth of Australia. Each state or territory government provides the funding and regulates the public and private schools within its governing area. The federal government funds the universities, but each sets its own curriculum. This has resulted in a raft of terminology, approaches and models being adopted.

A range of national reviews has been undertaken over time, exploring music, visual arts and dance or drama education. The Australian Senate Inquiry into Arts Education in 1995 found that "generalist primary classroom teachers, because of their own poor arts experience at school, and because of inadequate teacher preparation, lack confidence to teach the arts. As a result... there is a strong impulse to marginalise the arts in their teaching” (SERCARC 1995, 49). Ten years later the National Review of School Music Education (DEST, 2005) indicated that primary school teacher preparation does not adequately prepare generalist primary teachers to teach music in schools, attributing this in part to the reduction in hours dedicated to music in teacher preparation. Montague (2004) also draws attention to the reduction in hours in New South Wales (NSW) universities and the subsequent negative effect on teacher confidence in music education. The review identified improvement of teacher preparation as an immediate priority in the betterment of music education in Australian schools.

In 2005, the National Education and the Arts Statement (MCEETYA) was proposed as a vision for the future of arts education and is underpinned by three key principles:

1. All children and young people should have a quality arts education in every phase of learning

2. Partnerships should be created to strengthen community identity and local 
cultures

3. Schools should connect with the arts and cultural sector to enrich learning outcomes.

In 2008, the Melbourne Declaration on Educational Goals for Young Australians detailed the disciplines that the Australian curriculum, and in turn individual state and territory curricula, should encompass, and the arts are included in this list. The declaration commits to promoting equity and excellence in education and "to supporting all young Australians to become successful learners, confident and creative individuals, and active and informed citizens" (MCEETYA 2008, 8). The Australian curriculum will "equip all young Australians with the essential skills, knowledge and capabilities to thrive and compete in a globalised world and information rich workplaces of the current century" (p5). Currently Australia awaits the release of the Shape of the Australian Curriculum ${ }^{v}$ paper on the Arts to provide direction and indication of how the arts will be addressed within the national curriculum. In the meanwhile, teacher preparation in Australia continues to follow the existing conventions.

\section{Current south-south challenges in teacher preparation for syntegrated arts in primary schools}

Issues of teacher preparedness impact upon the quality of primary students' artistic learning and development in Australia, with a significant 'gap' being seen between the expectations of curriculum frameworks and teacher preparation in Arts education. The key interrelated issues are: pre-service teachers' confidence, attitudes, selfefficacy, and prior experiences in the art forms. The value pre-service teachers ascribe 
to Arts education and their self-efficacy and confidence in teaching the art forms affect both the amount and quality of arts that they teach once in schools (Dunkin 2004; Jeanneret et al. 2006; Klopper 2007; Russell-Bowie and Dowson 2005; Wright 1999).

A major problem regarding the implementation of arts teaching in South Africa is that the preparation of teachers does not correspond to the demands set by school practice (Vermeulen 2009, 6-5). The arts have unique methods of acquiring skills and knowledge. All the arts share a common feature: the culmination in a product, which has to be exhibited or performed in order to be shared and valued by the community (Stevenson and Deasy 2005, 28). This unique attribute bestows significance on arts experiences, since it focuses the concerted efforts and energies of all participants towards a purpose - the performance or exhibition. While most other subjects of the curriculum require almost identical responses from learners for an assignment, the arts demand unique and individual responses, which cannot simply be duplicated. It is therefore imperative that teachers in the arts are empowered to develop their own artistic skills and knowledge in order to involve learners in meaningful arts experiences. However, the acquisition and development of artistic skills and knowledge demand resources, resources that are compromised today due to national funding priorities and distribution within the higher education sector ${ }^{\mathrm{vi}}$ (Hocking 2009).

Alexander et al. (cited in Alter et al. 2009) declare the primary education curriculum "a far too demanding expectation of a generalist teacher's subject-knowledge”. Alter et al. (2009) suggest that, given this, Arts education is the subject that suffers most. Generalist teachers are perceived both by themselves and others as lacking the 
experience, training and subject knowledge to teach Arts education effectively.

Currently, one of the most important issues in South Africa is to improve the quality of teachers instead of simply producing large numbers of poorly prepared teachers. Furthermore, teachers need "skills, experience, knowledge and techniques" to be able to implement an arts curriculum (South Africa. DoE 2003, Foreword). This implies that "teachers have to be shown rather than told what to do", as Pandor, the former Minister of Education in South Africa, suggested (Pretorius and Gower 2009, 2). She continued by adding that "the department is now looking at better ways to train people”. The emphasis is therefore on high quality preparation of students for the demands of teaching practice, which should include first-hand experiences in the arts.

A key difficulty in implementing Arts education documented in the literature internationally is that of the 'crowded curriculum'. The arts often have a lower educational priority for schools and policy makers. The arts are also marginalised as a consequence of the push for a 'back to basics' approach focusing on literacy and numeracy (Brewer 2009; Horsley 2009). Research reflects the marginalisation of arts disciplines by terms such as “the narrowing of the curriculum” (Meyer 2004, 35) or the “ever-diminishing art education curriculum” (Grey 2010, 10). Enquiring about international trends in the training of students in Arts education, the research project The Arts Matter revealed noteworthy results. This project was launched in the UK, lasting from 1996 to 2000 (Harland et al. 2000). From this study it became clear that well taught arts programs lead to a range of advantageous outcomes for learners, schools, and the larger community. It was noted, however, that these positive outcomes were only observed where there was evidence of quality arts programs, 
implemented by well-trained arts educators (Bolton 2000, i). To assume that the general academic performance of learners will be boosted through random exposure to the arts is risking ridicule for arts programs. For policy makers the only way to make the arts-benefits connection work is via the provision of teachers with excellent skills in the arts. This places a huge responsibility on tertiary institutions where Arts teachers are educated.

A myth concerning the quality of Arts education implemented at primary schools is the belief that one can compensate for weak training in the subject field by strength in general teaching skills. Data gathered during Vermeulen's research indicated the manifestation of this myth (Vermeulen 2009). The main challenge, therefore, is to adequately prepare student teachers for Arts education by providing quality programs which include high levels of skills and knowledge development in at least two of the art forms. In this way, arts specialist teachers at schools can work together in syntegrated programs, balancing all the outcomes for the arts in an integrated fashion.

\section{Recommendations for policy makers in South Africa and Australia}

Despite the differences between South Africa and Australia, there are significant similarities in the recommendations that we believe need serious consideration by policy makers in both countries. One of these is the use of websites and networking to provide support for arts educators. Another recommendation is to enable co-operation between higher institutions, education departments and teachers to correlate the skills and knowledge content of teacher training programs. Our third recommendation is to promote streamlined curricula which advocate syntegrated arts programs. Lastly, we suggest that education departments establish focused arts programs to support specific 
knowledge and skills development, which promote continued involvement and learning in the arts. The next section gives a more detailed description of what each of these initiatives could involve.

\section{Websites}

The use of websites for resources is a means of providing material as well as supporting networking opportunities for primary school teachers nationally and internationally, and particularly in countries with large geographic distances, like South Africa and Australia. This can stimulate 'idea factories' where teachers share information and provide support and solutions to challenges faced during their daily experiences. Although most schools in South Africa do not have internet access or computers, this service could be used by mentor teachers and subject advisors to provide support for schools in disenfranchised areas during the cluster meetings which are held regularly, across the country. No textbook or document can replace the skills or knowledge that the individual has acquired and therefore these skills and knowledge need to be utilised as a necessary resource for the preparation of teachers. One example of such utilisation is www.artsmmadd.com - an online community of arts educators initiated to connect and share resources, opportunities and expertise globally (Russell-Bowie and Klopper 2009). This community is not restricted to practising arts educators; pre-service teachers can also become a part of the community and establish networks whilst still studying.

Another source of materials is the Teacher Education in Sub-Saharan Africa (TESSA) initiative, an open education resource for teacher education in Africa. Material for lessons can be downloaded from a free access website. This resource creates a dynamic interaction between teachers and pre-service students. It has subdivisions 
for various school phases as well as for specific learning areas. Although the available material for the Arts and Culture learning area is relatively limited on the TESSA website at present, it has the potential to extend considerably in the near future. It could also facilitate a subdivision promoting contributions from a variety of arts specialists. Policy makers should heartily endorse such resources.

\section{Higher Education}

Higher education institutions need to design course material appropriate for developing skills and knowledge of educators within the limited time and financial resources constraints. A major aim of teacher preparation should be to assist in the grounding of autonomous and professional teachers with high levels of appropriate knowledge and skills, specifically in discrete art forms. This aim needs to be realised through collaborative forums involving higher education institutions, national departments of education and practising educators.

A national and international framework for partnerships with higher education institutions, non-government organisations and the private sector would create the space for exchanges of services. This could create structured and systematic inservice programs for classroom teachers, school management teams and departmental support personnel.

\section{Curricula}

In South Africa, the benefits of a National Curriculum for the Arts and Culture learning area should be celebrated and emphasised, focusing on the major improvement of Arts and Culture being well-established as an official and assessed learning area. Yet a concerted effort is still necessary from specialists at universities and schools to change the perception of policy makers who often view the arts as 
elitist disciplines reserved for the privileged few. As reported by Horsley, central governments often establish that certain key disciplines, such as languages and maths, are "more mandatory" than a mandated music or arts curriculum (2009, 6). Policy makers should be influenced to realise the need for specialists in the arts disciplines in advising roles as First Education Specialists (FESs) at departmental level, in order to provide guidance and support to teachers in the field. A recommendation noted by the task team of the review report of the South African Curriculum (South Africa. DoE $2009,22)$ is that subject advisors need to be adequately trained regarding the specific needs and challenges of Arts education. Involving subject advisors in post-graduate courses in Arts education would be an important aspect in changing perspectives of the value and role of the arts in education. This could lead to high quality in-service training programs being offered, continuously enhancing the provision of Arts education.

Similarly, Australia should continue to take note of international Arts education offerings to support the development of a $21^{\text {st }}$ century curriculum that would bring national unity in design and terminology but also provide for local propensity and ownership. Applying a syntegrated model with co-ordinated programs, and team teaching by various travelling arts specialists, could lead to a positive outcome for the implementation of Arts education.

Where Arts education is in a survival mode, the utilitarian role of the arts in the overall curriculum, implemented as vital tools in developing communication, listening, language and literacy skills as well as general brain development for all learners, should be promoted. However, the most important motivation for arts 
education should remain the intrinsic and unique qualities which only the arts can teach (Grey 2010, 10).

\section{Focused Programs}

Various provinces in South Africa have initiated projects to promote the arts. In the Gauteng region, for example, magnet schools have been set up where learners are involved in extra-curricular activities in the arts (Pandor 2007, 1). This Extra-Mural Education Project or EMEP supports schools to "grow as learning and recreational hubs within their communities” and to “energise the curriculum”. In the Cape region, focus schools are implemented where all the art forms are presented to learners who wish to continue in one of the arts in the FET phase (Further Education and Training phase, school grades 10-12).

Similarly, focused arts education programs operate in Australian schools: Learning to learn through the Arts@Direk Primary School, South Australia; SCRAYP - Youth Arts With an Edge: Footscray Community Arts Centre, Victoria; The Northern Territory Indigenous Music Education Programme; and The Northern Territory Boys' Business Music Programme (Klopper and Power, 2010). These programs have been studied for the impact of each on students' academic progress, engagement with learning and attendance at school, as well as to identify attributes of arts programs deemed to be of particular benefit to students. Overall there were no statistically significant results to indicate that involvement in these programs increased academic or learning outcomes; however, there was evidence across the four sites studied that these arts programs did encourage students to engage with school and with learning. Attributes of these focused arts programs identified as particularly beneficial to students were: a charismatic/inspirational role model for students; positive reinforcement of students' achievements; authentic activities working towards public 
presentation; familiar/negotiated procedures and a 'safe' environment for risk taking. For these very reasons focused arts program initiatives should wholeheartedly be supported by policy makers.

\section{International South-South Networking}

We would particularly like to see other southern hemisphere countries becoming part of a south-south networking. Despite possible language barriers there are several distinct and relevant similarities between southern, as opposed to northern, hemisphere countries. One of the first ways to accomplish this is the use of the website created for the arts by Russell-Bowie and Klopper, which should be expanded to include inter alia South African arts educators. The internet is a powerful and efficient tool which can be utilized between cultures and countries and which can extend and replicate support systems for arts educators across the globe. Since Arts education has similar - though not identical - challenges in most countries, it would be to the benefit of all if there is a better understanding, support and cooperation to uplift the curricula of arts programs internationally.

Any curriculum requires regular revision. However, a basic arts curriculum - which is realistic, feasible and practical for teachers to implement - should be compiled to provide a solid base to work from, especially for generalist teachers delivering Arts education. Where the norm for curricular development is a "top-down policy" from governmental level (Horsley2009, 11), we recommend that input from arts educators in practice be obtained to create an 'inside-out' approach. As Brewer comments: "legislators are not the right people to be making decisions about arts education policy: they do not have the expertise” (2009, 30). The success of the implementation 
of any arts program lies chiefly in the quality of the teachers. Wiggins and Wiggins (2008, p. 3-4) assert that "we need to present policy makers with descriptions of what actually occurs in primary classrooms when generalist teachers teach music so they will have accurate criteria for making decisions about the future of music education in the schools".

We reiterate this sentiment, extending it to include all art forms, but further the call to include a closer examination of classroom-based arts education practice. What are teachers in our classrooms actually doing in relation to teaching arts education? In our view, the heart of curriculum transfer and transformation is in the classroom. Not only do we need to attend to the situation at this level, as well as to the preparation of teachers for a syntegrated arts classroom practice, but the disjuncture between policy and practice, reported internationally, needs constant monitoring. Only with the support from policymakers - who determine the allocation of time and resources available for arts education - can teachers implement a curriculum which effectively syntegrates arts education. 


\section{References}

Aaron, J. 1994. Integrating music with core subjects. Music Educators Journal 80(6): 27-33.

Alter, F., T. Hays and R. O’Hara. 2009. Creative Arts Teaching and Practice: Critical Reflections of Primary School Teachers in Australia. International Journal of Education \& the Arts 10 (9): 1-21.

Barrett, J. R. 2001. Interdisciplinary work and musical integrity. Music Educators Journal 87(5): 27-31.

Bolton, E. 2000. Foreword. In Arts Education in Secondary Schools: Effects and Effectiveness, edited by Harland, J., K. Kinder, P. Lord, A. Stott, I. Schagen, J. Haynes, L. Cusworth, R. White and R. Paola. London: ACE, LGA, NFER, RSA.

Brewer, T. M. 2009. Arts Education Policy Lessons Learned from the Southeastern Collage Art Conference. Arts Education Policy Review, 110(3), 35-39.

Brinkman, D. J. 2010. Teaching Creatively and Teaching for Creativity. Arts Education Policy Review 111: 48-50.

Burton, L. H. 2001. Interdisciplinary Curriculum: Retrospect and prospect. Music Educators Journal 87(5): 17-21, 66. 
Chrysostomou, S. 2004. Interdisciplinary approaches in the new curriculum in Greece: a focus on music education. Journal for Research in Music Education, 105(5): 23-29.

Consortium of National Arts Education Associations. 2002. Authentic Connections: Interdisciplinary Work in the Arts. Reston, VA.

Department of Education, Science and Training (DEST). 2005. National Review of School Music Education: Augmenting the Diminished.

http://www.dest.gov.au/sectors/school_education/publications_resources/profiles/scho ol_music_education.htm\#publication.

Dunkin, A. 2004. 'Gliding glissade not grand jete: Elementary classroom teachers teaching dance', Arts Education Policy Review, 105(3): 23-29.

Grey, A. C. 2010. No Child Left Behind in Art Education Policy: A Review of Key Recommendations for Arts Language Revisions. Arts Education Policy Review, 111: 8-15.

Harland, J., K. Kinder, P. Lord, A. Stott, I. Schagen, J. Haynes, L. Cusworth, R. White and R. Paola. 2000. Arts Education in Secondary Schools: Effects and Effectiveness. London: ACE, LGA, NFER, RSA.

Hauptfleisch, S. 1997. Transforming South African music education: a systems view. 
Unpublished D.Mus. thesis. University of Pretoria.

Hocking, R. 2009. National audit of music discipline and music education mandatory content within pre-service generalist primary teacher education courses: a report. Sydney: Music Council of Australia.

Horsley, S. 2009. The Politics of Public Accountability: Implications for Centralized Music Education Policy Development and Implementation. Arts Education Policy Review, 110(4): 6-12.

Jeanneret, N., Brown, R., Bird, J., Sinclair, C., Imms, W., Watkins, M. and Donelan, K. 2006. 'Encounters with engaging pedagogy: Arts education for the pre-service primary generalist', In Backing our creativity: Proceedings from the national education and the arts symposium, (eds.), N. Jeanneret and G. Gardiner. Sydney: Australian Council for the Arts.

Jones, P.M. 2009. Hard and Soft Policies in Music Education: Building the Capacity of Teachers to Understand, Study, and Influence Them. Arts Education Policy Review 110 (4): 27-32.

Klopper, C. J. 2004. Variables impacting on the delivery of music in the learning area arts and culture in South Africa. Unpublished D.Mus. thesis. University of Pretoria.

Klopper, C. J. 2007. So you gotta teach music! A case for advocacy in regional Australian teacher education. In ASME XVI 40th Anniversary National Conference. 
Perth, Western Australia.

Klopper, C. and Power, B. 2010). 'Illuminating the gap: An overview of classroombased arts education research in Australia', International Journal of Education through Art 6 (3): 293-308.

Levine, L. 2005. The Drumcafé's traditional music of South Africa. Johannesburg: Jacana.

Loepp, F.L. 1999. Models of Curriculum Integration [Electronic Version]. The Journal of Technology Studies, XXV, 1-17. Retrieved October 2, 2006 from http://scholar.lib.vt.edu/journals/TOTS/Summer-Fall-1999/Loepp.html.

MCEETYA. 2008. Melbourne declaration on educational goals for young Australians. Retrieved June 9, 2010 from

http://www.curriculum.edu.au/verve/_resources/National_Declaration_on_the_Educat ional_Goals_for_Young_Australians.pdf.

Meyer, L. 2004. The complete curriculum: Ensuring a place for the arts and foreign languages in America's schools. Arts Education Policy Review, 106(3), 35-39.

Montague, J. 2004. Policy to Practice: Arts Action and Support for the Non-Specialist Teacher in the K-6 Classroom. In International Society of Music Education Conference, edited by David Forrest, 141-55. Nedlands WA: International Society for Music Education. 
Nzewi, M. 2003. Acquiring knowledge of the musical arts in traditional society. In A.

Herbst, M. Nzewi \& K. Agawu (Eds.), Musical arts in Africa: theory, practice and education (pp. 13-37). Pretoria: University of South Africa.

Oehrle, E. 2002. Towards a Philosophy of Education through Music/Arts for Southern Africa. In C. van Niekerk (Ed.), PASMEC 2001: Selected Conference Proceedings from the Conference held in Lusaka, Zambia, 21-25 August 2001 (pp. 104-114). Pretoria: PASMAE.

Pandor, N. 2007. Address by the Minister of Education, Naledi Pandor MP, at the Extra-Mural Education Project's 'Beyond the School Wall' teachers' graduation, Sid G Rule Primary School, Grassy Park, Cape Town, 21st April 2007.

Pretorius, C. and Gower, P. 2009. On track to perform better. The Teacher, 14(5): 2.

Rijsdijk, A. S. C. 2003. An investigation into the state of music education in the learning area Arts and Culture in primary schools of the Western Cape Metropole. Unpublished M.Mus. dissertation. University of Cape Town.

Russell-Bowie, D. 2006. MMADD about the arts! An Introduction to Primary Arts Education. Frenchs Forest NSW, Australia: Pearson Prentice Hall.

Russell-Bowie, D. 2008. Integrate or Syntegrate? Models for Integrating Music across the primary school. Paper presented at the ISME Conference, Bologna, Italy. 
Russell-Bowie, D. and C. J. Klopper. 2009. http://artsmmadd.com.

Russell-Bowie, D. and Dowson, M. 2005. 'Effects of background and sex on confidence in teaching the creative arts: Tests of specific hypotheses', In Australian Association for Research in Education Conference. Sydney.

SERCARC. 1995. Arts Education. Edited by Recreation Senate Environment, Communication and the Arts Reference Committee. Canberra: SERCARC.

Snyder, S. 2001. Connection, Correlation, and Integration. Music Educators Journal 87(5): 32-40.

South Africa. DoE. (2002). Revised National Curriculum Statement Grades R-9 (Schools). Policy: Arts and Culture. Pretoria: Department of Education.

South Africa. DoE. (2003). Revised National Curriculum Statement Grades R-9 (Schools). Teacher's Guide for the development of learning programmes: Arts and Culture. Pretoria: Department of Education.

South Africa. DoE. 2009. Report of the Task Team for the Review of the Implementation of the National Curriculum Statement. Pretoria.

Stevenson, L. M., \& Deasy, R. J. 2005. Third Space: when learning matters. Washington, DC: Arts Education Partnership. 
TESSA. Teacher education in Sub Saharan Africa: Open educational resources for teacher education in Africa. www.tessafrica.net.

Vermeulen, D. 2009. Implementing music in an integrated arts curriculum for South African primary schools. Unpublished D.Mus thesis, University of Pretoria.

Wiggins, R. and J. Wiggins. 2008. Primary music education in the absence of specialists. International Journal of Education \& the Arts 9: 1-26.

Wright, P. 1999. 'The thought of doing drama scares me to death', Research in Drama Education: The Journal of Applied Theatre and Performance 4: 2, 227-237.

\footnotetext{
${ }^{\mathrm{i}}$ Gauteng (Sotho for place of gold) is one of nine provinces in South Africa.

${ }^{\text {ii }}$ In syntegrated Arts education, the interactions among the arts are the links, both epistemological and human, which allow for the possibility of guided experiential arts development. Such an approach secures the survival of curricular attention to the various art disciplines. The focus is on the process in its entirety and not the end product alone. The process aims for the development of skills and knowledge, not just what may result from unguided experiential learning. This approach is derived from an optimistic vision for Arts education that offers core content and interdisciplinary modules and/or units, which are elective according to the needs of the learner and the demographics of the community. The culminating result is a syntegrated arts learning experience.

iii These include both hard and soft policies, as were described by Patrick M. Jones in his article on that topic in the Summer 2009 (vol. 110 No. 4) of this journal.

${ }^{\text {iv }}$ In this article the terms learner(s) and student(s) are used, but not pupil(s); teacher(s) and lecturer(s) are used, not facilitator(s).

${ }^{\mathrm{v}}$ See for further details pertaining to The Shape of the Australian Curriculum
} 
http://www.acara.edu.au/development_of_the_australian_curriculum.html

${ }^{\text {vi }}$ Although Hocking is referring to the situation in Australia, exactly the same applies in South Africa. 